\title{
COMPARISON OF MODERATE-TO-VIGOROUS PHYSICAL ACTIVITY LEVELS BETWEEN PHYSICAL EDUCATION, SCHOOL RECESS AND AFTER-SCHOOL TIME IN SECONDARY SCHOOL STUDENTS: AN ACCELEROMETER-BASED STUDY
}

\author{
Daniel Mayorga-Vega', Maribel Parra Saldías ${ }^{2}$, and Jesús Viciana ${ }^{1}$ \\ ${ }^{1}$ Department of Physical Education and Sport, University of Granada, Spain \\ ${ }^{2}$ Observatorio del Deporte, Universidad de Los Lagos, Chile
}

Original scientific paper

UDC: 796.012.13:613-053.6

\begin{abstract}
:
Regular physical activity is an important factor of health in youth. Unfortunately, in Chile $85 \%$ of adolescents do not achieve the recommended 60 min daily moderate-to-vigorous physical activity. Physical education, school recess and after-school time are considered crucial environments for adolescents to meet the recommended moderate-to-vigorous physical activity levels. This study compared the moderate-tovigorous physical activity levels between physical education, school recess and after-school time in Chilean secondary school students, and examined the influence of gender and weight status. A hundred and fifty-six Chilean secondary school students (finally 89 participants were included), aged 13-14 years, were monitored by objective measures of moderate-to-vigorous physical activity during physical education, school recess and after-school time. Results indicated statistically significant differences in moderate-to-vigorous physical activity between contexts (total minutes: after-school time>physical education $>$ school recess; percentage: physical education $>$ after-school time $=$ school recess, $\mathrm{p}<.001$ ) as well as a gender-related influence (boys $>$ girls, $\mathrm{p}<.05)$. Policy-makers are encouraged to increase the number of physical education classes and teachers to ensure that more physical education class time is spent in moderate-to-vigorous physical activity, especially among girls. The increase in students' moderate-to-vigorous physical activity levels during school recess and after-school time should also be promoted.
\end{abstract}

Key words: accelerometry, exercise, healthy behavior, public health, adolescence, youth

\section{Introduction}

Engagement in regular physical activity (PA) is an important factor of health and quality of life in youth (Poitras, et al., 2016), especially due to the demonstrated relationship with the maintenance of an active life later during adulthood (Longmuir, Colley, Wherley, \& Tremblay, 2014). The World Health Organization (WHO) recommends that children and adolescents should daily achieve at least 60 minutes of moderate-to-vigorous PA (MVPA) (WHO, 2014). Unfortunately, young people are currently insufficiently physically active (WHO, 2014), especially during adolescence when their MVPA levels drop drastically (Silva, et al., 2011; Zimmermann-Sloutskis, Wanner, Zimmermann, \& Martin, 2010). About $81 \%$ of adolescents worldwide and $85 \%$ of adolescents particularly in Chile $(91 \%$ girls and $80 \%$ boys) do not achieve the daily recommendation of 60 minutes of MVPA (WHO, 2014).

Consequently, an important health priority of the WHO member states is nowadays the promo- tion of adolescents' MVPA levels (WHO, 2014). Together with the other WHO member states, Chile has targeted at reducing $10 \%$ of the prevalence of insufficient PA by 2025 (WHO, 2014). Although strategies to improve PA must be developed and implemented through multiple sectors (WHO, 2014), schools have been considered as key environments for adolescents' PA promotion (WHO, 2008). Particularly, physical education (PE), due to its compulsory character and guided by capable professionals, has been considered as an ideal setting for promoting higher MVPA levels in youth (WHO, 2008). Moreover, a recent study has shown how PE days have been identified with higher MVPA levels than non-PE days (Viciana, Mayorga-Vega, \& Parra Saldías, 2017), contributing significantly to the overall students' daily MVPA. Schools are encouraged to ensure that the majority of PE class time is spent in PA (WHO, 2008), but PE classes often do not meet the recommendation of at least $50 \%$ of time dedicated to MVPA for adolescents 
(Fairclough \& Stratton, 2005; WHO, 2006). Inspite a wide heterogeneity of results in the previous related studies (Fairclough \& Stratton, 2005), data with the Chilean adolescents were not found. Additionally, in Chile PE potential is restricted by its limited curriculum time allocation, especially during secondary schooling when time allocation is even more reduced than during primary school (Hardman, Murphy, Routen, \& Tones, 2014).

Extra-curricular time such as school recess (SR) and after-school time (AS) could provide supplemental PA opportunities for adolescents to meet the recommended MVPA levels (WHO, 2008). Previous studies have shown that SR contributes $5-40 \%$ of the recommended daily MVPA levels (Ridgers, Stratton, \& Fairclough, 2006). Apart from some exceptions, such as Portugal where the school schedule is very long with various SR periods during a day, SR periods contribute more comprehensively to the total amount of the daily recommended MVPA (about 40\%) (Silva, Sousa, Sá, Ribeiro, \& Mota, 2015). In Chile, secondary school students also have a large SR time each school day, however, related data are still unknown to date. On the other hand, AS is the third school-day period for students where MVPA could be increased (Viciana, Mayorga-Vega, \& Martinez-Baena, 2016). Findings on PA during this period are also discrepant and variable depending on multiple factors (Lee, et al., 2015), and also no previous studies with Chilean secondary school students were found. Despite the fact that these previous two contexts are the most important extra-curricular periods of the day, as regards the contribution to the MVPA recommendations (Arundell, et al., 2013; Ridgers, et al., 2006), PA practice depends mainly on the selfchoices and will of the students (Mayorga-Vega \& Viciana, 2014). In this line, and according to the last national report about PA in Chilean children and adolescents (Cortinez-O'Ryan \& Aguilar-Farias, 2017), less than $25 \%$ of school-age children practice PA outside the compulsory PE lessons.

Physical activity is a multidimensional and complex behavior that tends to vary considerably depending on individual factors (Bauman, Sallis, Dzewaltowski, \& Owen, 2002). Among the individuals' characteristics, gender has been considered as one of the most important (Bauman, et al., 2002), but others, such as weight status (Gao, Oh, \& Sheng, 2011), cannot be disregarded either. To determine the influence of these individual factors on adolescents' MVPA levels, the PE, SR and AS time is crucial to be investigated for the achievement of the recommended MVPA levels (MayorgaVega \& Viciana, 2015; Viciana, Mayorga-Vega, \& Martinez-Baena, 2016). Most previous studies have separately examined the objectively-measured MVPA levels during PE lessons, SR and AS among adolescents, and/or the influence of personal factors on PA levels in these settings with mixed outcomes (Fairclough \& Stratton, 2005; Ridgers, Salmon, Parrish, Stanley, \& Okely, 2012; Slingerland, Borghouts, \& Hesselink, 2012; Viciana, Martínez-Baena, \& Mayorga-Vega, 2015). To our knowledge only Viciana et al. (2016) compared the objectively-measured MVPA levels in all the three contexts, as well as the influence of individual factors within the same sample (Spanish adolescents). The authors found that Spanish secondary school students had a higher total time of MVPA during AS time than during PE and SR time and a higher MVPA in PE than in SR. However, taking into account the total daily time considered for each of the periods (600 minutes for AS, 30 minutes for $\mathrm{SR}$, and 60 minutes for PE), PE was the period with the highest percentage of time adolescents were involved in MVPA (27\%), followed by SR (11\%) and AS (7\%). Regarding the individual factors, Viciana et al. (2016) found that boys were involved in MVPA more than girls in each of the contexts analyzed, but differences between weight status profiles were not found except for the AS time.

Moderate-to-vigorous physical activity outcomes also vary depending on culture-related factors in each particular country (Bauman, et al., 2002). For instance, in the meta-analysis of PA levels among young people around the world, performed by Brooke, Corder, Atkin, and van Sluijs (2014), the cross-study heterogeneity was high due to cultural variations, among other reasons. Related studies with Chilean adolescents were not found. Among Chilean adolescents only a few studies of overall PA have been found, based on a selfreported assessment (e.g., Burrows, et al., 2008; Muros, et al., 2016). However, this method has been evidenced to have limited validity in youth (Sternfeld \& Goldman-Rosas, 2012).

In order to promote Chilean adolescents' MVPA levels and thus reaching the proposed target of reducing the prevalence of insufficient PA by the year 2025 (WHO, 2014), a better understanding is necessary of the complex relationship between PA, individuals' characteristics, and PA contexts in the Chilean environment. As commented by Moreno, Concha, and Kain (2012) in their perspectives for the future, it is important to address the real contribution of these key environments not only to the total daily MVPA, but also to relate them with the recommended $60 \mathrm{~min} /$ day in the Chilean adolescents. Therefore, in addition to the average total time and percentage of total time, analyzed by Viciana et al. (2016), an average percentage of the recommended daily MVPA achieved by the adolescents should be also analyzed. To our knowledge, there are no studies that compare the objectivelymeasured MVPA levels in the three contexts or the influence of individual factors on PA levels among Chilean secondary school students. 
Firstly, this information may help policymakers to get an insight into the real PA levels among adolescents in the Chilean context. Then, based on these insights, policy-makers will be able to select the most appropriate strategies and programs for promoting the recommended MVPA levels among Chilean adolescents in these important contexts, thus contributing significantly to the overall students' daily MVPA levels and reaching the proposed target of reducing the prevalence of insufficient PA by the year 2025. Consequently, the purposes of the present study were: (a) to compare the objectively-measured MVPA levels (expressed as total time, percentage of total time and percentage of achieving the daily recommended MVPA) between PE lessons, SR, and AS in Chilean secondary school students, and (b) to examine the influence of gender and weight status on students' objectively-measured MVPA levels (expressed as total time, percentage of total time and percentage of achieving the daily recommended MVPA) during $\mathrm{PE}$ lessons, SR and AS in Chilean secondary school students.

\section{Methods}

\section{Participants}

A sample of 156 Chilean secondary school students, 87 boys and 69 girls, eighth graders of municipalized basic education level schools (i.e., 13-14 years of age) agreed to participate in the present study and met the inclusion criteria. All the students came from the district called Nuñoa (Santiago de Chile, Chile). The inclusion criteria were: (a) being enrolled in the eighth grade of any selected school; (b) participating in the regular PE classes; (c) being free of any health disorder which might make them unable to undergo PA, and (d) presenting the corresponding consent signed by their parents or legal guardians. The exclusion criteria were: (a) not having at least $95 \%$ of the PE sessions recorded; (b) not having at least three of the five SR periods with at least $95 \%$ of the registered time, and (c) not having at least three of the five AS with at least $360 \mathrm{~min}$ recorded. Out of the initial number of participants $(\mathrm{N}=156)$, only 89 passed the exclusion criteria and thus they were included in further analysis. Besides the 51 students who were eliminated due to meeting one or more exclusion criteria, data of 16 students were excluded because their PE classes were suspended due to the environmental alert.

\section{Measures}

Moderate-to-vigorous physical activity levels. Objectively-measured MVPA was assessed by a GT3X accelerometer (ActiGraph, LLC, Pensacola, FL, USA). The GT3X accelerometer is a compact $(3.8 \times 3.7 \times 1.8 \mathrm{~cm})$, lightweight $(27 \mathrm{~g})$, and triaxial monitor designed to record time of varying accelerations ranging in magnitude from approximately 0.05 to $2.50 \mathrm{Gs}$. The accelerometer output is digitized by a 12-bit analog-to-digital converter at rates of 30-100 Hz. Then, the signal passes through a digital filter that band limits the accelerometer to the frequency range of $0.25-2.5 \mathrm{~Hz}$. The filtered signal is then rectified and integrated over a user-specified interval time known as epoch. At the end of each epoch, the summed value know as "activity count" or counts is stored in memory and the integrator is reset. The counts obtained in a particular epoch are proportional to the intensity of the PA during the measured period (Trost, Loprinzi, Moore, \& Pfeiffer, 2011).

After students' PA was monitored, data were downloaded and analysed using the ActiLife Lifestyle Monitoring System Software, version 6.13.2. $\mathrm{PE}$ and SR were registered according to the schools' schedules. AS was registered from the end of the school time to the end of the day (i.e., 23:59 h). To determine the time engaged in MVPA, Evenson's cut-off points (i.e., $\geq 2,296$ counts/min) were used (Trost, et al., 2011). Then, in addition to the total time of MVPA in each studied period, the percentage of the 60 min daily recommendation of MVPA and the percentage of MVPA time within the total time period registered were also calculated. ActiGraph accelerometer-measured PA has shown a high reliability and validity among adolescents (Santos-Lozano, et al., 2013; Trost, et al., 2011).

Weight status. Participants' weight status was categorized according to the international cut-off values of the body mass index (BMI) as not-overweight (BMI<overweight cut-point) and overweight (BMI $\geq$ overweight cut-point) (Cole, Bellizzi, Flegal, $\&$ Dietz, 2000). For this purpose, first participants' body mass and height were measured and then the BMI was calculated as body mass divided by body height squared $\left(\mathrm{kg} / \mathrm{m}^{2}\right)$. Body mass and height were measured while participants were shorts, T-shirts, and barefoot. For the body mass measure, the participant stood in the centre of the scale (Tanita HD 313, Arlington, IL, USA; accuracy $=0.1 \mathrm{~kg}$ ) without support and with the weight distributed evenly on both feet. For the body height assessment, students stood with the feet together with the heels, buttocks and upper part of the back touching the stadiometer (SECA 206 ${ }^{\circledR}$, Hamburg, Germany; accuracy $=0.1$ $\mathrm{cm}$ ), and with the head placed in the Frankfort plane. Two measurements of both body mass and height were performed and then the average of each was calculated (International Society for the Advancement of Kinanthropometry, 2001).

\section{Procedures}

The protocol of the present study was first approved by the Ethical Committee of the University of Granada. Then, the principals and the PE 
teachers of all the 10 municipalized schools of basic education level belonging to the Community of Nuñoa (Santiago de Chile, Chile) were contacted by a researcher. They were informed about the project and the permission to conduct the study was requested. After approvals of four schools were obtained, eighth-grade students and their legal guardians were fully informed about all the features of the study [i.e., a thorough description of the methods, potential risks, expected benefits, etc.; based on Thomas, Nelson, and Silverman's (2011) guidelines], and written informed consent was obtained from all the participants' legal guardians to take part in the study.

Data were collected during the months from July to October of 2015. During a PE class, a trained researcher fitted the accelerometers on the right hip of all the participants by using an elastic waistband. Participants were instructed to wear the accelerometer for eight consecutive days. Participants were asked to wear the accelerometer from waking to bedtime and to take the accelerometer off only when engaged in aquatic activities or taking a shower. PE lessons were developed following the program designed by the teachers. During SR, participants were allowed to do every activity they usually do; which means they were in an unstructured and free choice time. In the AS, students were urged to maintain their normal PA habits and were encouraged to continue with organized sports activities during the monitored week. Afterwards, a trained researcher collected anthropometric measurements during a PE class.

\section{Statistical analyses}

Descriptive statistics (mean and standard deviation) for all the variables were calculated. Then, one-way analyses of variance (ANOVA) were conducted to examine potential differences between boys and girls in terms of body mass, body height and BMI. Additionally, a chi-squared analysis was carried out to test if boys and girls had a balanced representation of not-overweight and overweight participants. As the MVPA variables did not follow a normal distribution, the data was previously transformed using a logarithm (Bland \& Altman, 1996).
One-way analyses of covariance (ANCOVA), with gender and BMI values as covariates, were used to examine the differences in MVPA levels between $\mathrm{PE}, \mathrm{SR}$, and AS in the whole sample. Subsequently, the post-hoc with the Bonferroni adjustment was used for within-groups pairwise comparisons. Afterward, two groups (boys, girls) $\times$ three contexts (PE, SR, AS) ANCOVA, with BMI values as covariates, were used to test the influence of gender on the MVPA levels. Subsequently, a post-hoc with the Bonferroni adjustment was used for both between and within-groups pairwise comparisons. Similarly, to examine the influence of weight status on MVPA levels, gender was used as a covariable. Effect sizes were estimated using the partial eta squared $\left(\eta^{2}\right)$. All statistical analyses were performed using the SPSS Version 21.0 for Windows (IBM $₫$ SPSS $\AA$ Statistics). The statistical significance level was set at $\mathrm{p}<.05$.

\section{Results}

In Table 1 general characteristics of the included participants are presented. The one-way ANOVA results did not show statistically significant differences in body mass and BMI values between boys and girls ( $p>05)$. However, boys were statistically significantly taller than girls $(\mathrm{p}<.05)$. The chi-square analysis showed that the boys and girls categories had a balanced representation of not-overweight and overweight participants $(\mathrm{p}>0.05)$.

Table 2 shows descriptive statistics (mean and standard deviations) and ANCOVA results of the comparison of MVPA levels between PE, SR and AS for the whole sample, as well as for gender and weight status categories.

\section{The whole sample}

The one-way ANCOVA results indicated statistically significant differences in the average MVPA levels between PE, SR and AS $(\mathrm{p}<.05)$. Then, the post-hoc within-group pairwise comparisons with the Bonferroni adjustment showed statistically significant higher values of average total time and average percentage of achieving the daily recommended MVPA in AS than in PE and SR, and greater MVPA values in PE than in SR $(\mathrm{p}<.001)$.

Table 1. General characteristics (mean \pm standard deviation/frequency) of the included participants and differences between boys and girls

\begin{tabular}{lcccc}
\hline & Total $(\mathrm{N}=89)$ & Boys $(\mathrm{n}=55)$ & Girls $(\mathrm{n}=34)$ & $\left.\mathrm{p}^{\mathrm{a}}\right)$ \\
\hline Age (years) & $13.4 \pm 0.7$ & $13.5 \pm 0.7$ & $13.3 \pm 0.6$ & - \\
Body mass $(\mathrm{kg})$ & $58.5 \pm 10.7$ & $59.0 \pm 11.2$ & $57.8 \pm 9.8$ & .628 \\
Body height $(\mathrm{cm})$ & $163.8 \pm 7.2$ & $165.9 \pm 7.4$ & $160.3 \pm 5.5$ & $<.001$ \\
Body mass index $\left(\mathrm{kg} / \mathrm{m}^{2}\right)$ & $21.8 \pm 3.6$ & $21.4 \pm 3.6$ & $22.5 \pm 3.6$ & .159 \\
Not-overweight/overweight & $60 / 29$ & $39 / 16$ & $21 / 13$ & .371 \\
\hline
\end{tabular}

Note. a Significance level from the one-way analysis of variance for body mass, height and BMI, and from the chi-squared test for the not-overweight/overweight ratios. 
Table 2. Comparison of moderate-to-vigorous physical activity levels between physical education, school recess and after-school time $^{a}$

\begin{tabular}{|c|c|c|c|c|c|c|c|c|c|c|}
\hline & & \multirow{2}{*}{$\begin{array}{c}\begin{array}{c}\text { Physical } \\
\text { education (1) }\end{array} \\
\mathrm{M} \pm \mathrm{SD}\end{array}$} & \multirow{2}{*}{$\begin{array}{c}\begin{array}{c}\text { School } \\
\text { recess (2) }\end{array} \\
\mathrm{M} \pm \mathrm{SD}\end{array}$} & \multirow{2}{*}{$\begin{array}{c}\begin{array}{c}\text { After-school } \\
\text { time }(3)\end{array} \\
\mathrm{M} \pm \mathrm{SD}\end{array}$} & \multicolumn{3}{|c|}{ ANCOVA $^{b}$} & \multicolumn{3}{|c|}{ Pairwise comparisons ${ }^{c}$} \\
\hline & & & & & $\mathrm{F}$ & $\mathrm{p}$ & $\eta_{p}^{2}$ & $1-2$ & $2-3$ & $1-3$ \\
\hline \multicolumn{11}{|l|}{ The whole sample } \\
\hline Total $(\mathrm{N}=89)$ & Total time & $11.05 \pm 8.15$ & $4.43 \pm 6.31$ & $21.47 \pm 13.82$ & 4.032 & .019 & .045 & $<.001$ & $<.001$ & $<.001$ \\
\hline Total $(\mathrm{N}=89)$ & $\% 60 \mathrm{~min}$ & $18.41 \pm 13.58$ & $7.39 \pm 10.52$ & $35.79 \pm 23.03$ & 4.080 & .019 & .045 & $<.001$ & $<.001$ & $<.001$ \\
\hline Total $(\mathrm{N}=89)$ & $\%$ total time & $13.16 \pm 9.96$ & $6.94 \pm 9.30$ & $4.55 \pm 3.01$ & 4.577 & .014 & .051 & $<.001$ & 1.000 & $<.001$ \\
\hline \multicolumn{11}{|l|}{ Gender } \\
\hline Boys $(n=55)$ & Total time & $12.95 \pm 8.63^{*}$ & $6.21 \pm 7.37 \dagger$ & $23.69 \pm 14.72$ & 3.526 & .032 & .039 & $<.001$ & $<.001$ & $<.001$ \\
\hline Girls $(n=34)$ & & $7.97 \pm 6.27$ & $1.56 \pm 1.87$ & $17.88 \pm 11.53$ & & & & $<.001$ & $<.001$ & $<.001$ \\
\hline Boys $(n=55)$ & $\% 60 \min$ & $21.58 \pm 14.38^{*}$ & $10.35 \pm 12.29 \dagger$ & $39.48 \pm 24.53$ & 4.343 & .014 & .048 & $<.001$ & $<.001$ & $<.001$ \\
\hline Girls $(n=34)$ & & $13.28 \pm 10.46$ & $2.60 \pm 3.12$ & $29.81 \pm 19.22$ & & & & $<.001$ & $<.001$ & $<.001$ \\
\hline Boys $(n=55)$ & $\%$ total time & $15.34 \pm 10.64^{*}$ & $9.71 \pm 10.75 \dagger$ & $5.06 \pm 3.23^{*}$ & 5.812 & .005 & .063 & $<.001$ & .138 & $<.001$ \\
\hline Girls $(n=34)$ & & $9.63 \pm 7.63$ & $2.47 \pm 2.83$ & $3.72 \pm 2.45$ & & & & $<.001$ & .018 & $<.001$ \\
\hline \multicolumn{11}{|l|}{ Weight status $^{d}$} \\
\hline $\begin{array}{l}\text { Not-overweight } \\
(n=60)\end{array}$ & Total time & $11.13 \pm 7.87$ & $4.15 \pm 6.18$ & $21.09 \pm 14.38$ & 1.238 & .293 & .014 & $<.001$ & $<.001$ & $<.001$ \\
\hline Overweight $(n=29)$ & & $10.86 \pm 8.83$ & $5.01 \pm 6.64$ & $22.26 \pm 12.77$ & & & & $<.001$ & $<.001$ & $<.001$ \\
\hline $\begin{array}{l}\text { Not-overweight } \\
(\mathrm{n}=60)\end{array}$ & $\% 60 \mathrm{~min}$ & $18.56 \pm 13.12$ & $6.92 \pm 10.31$ & $35.15 \pm 23.97$ & 1.443 & .239 & .017 & $<.001$ & $<.001$ & $<.001$ \\
\hline Overweight $(n=29)$ & & $18.10 \pm 14.71$ & $8.36 \pm 11.07$ & $37.11 \pm 21.28$ & & & & $<.001$ & $<.001$ & $<.001$ \\
\hline $\begin{array}{l}\text { Not-overweight } \\
(\mathrm{n}=60)\end{array}$ & $\%$ total time & $13.31 \pm 9.77$ & $6.44 \pm 8.91$ & $4.42 \pm 3.11$ & 1.683 & .191 & .019 & $<.001$ & 1.000 & $<.001$ \\
\hline Overweight $(n=29)$ & & $12.86 \pm 10.50$ & $7.98 \pm 10.13$ & $4.81 \pm 2.84$ & & & & .021 & 1.000 & $<.001$ \\
\hline
\end{tabular}

Note. $M$ = Mean; SD = standard deviation; Total time = average total time in minutes of moderate-to-vigorous physical activity levels; $\% 60 \mathrm{~min}=$ average percentage of achieving the 60 min daily recommendation of moderate-to-vigorous physical activity levels;

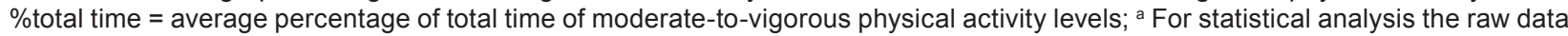
were transformed by the logarithm; ' One-way ANCOVA for the whole sample and two-way ANCOVA for gender and weight status; ${ }^{c}$ Post-hoc pairwise comparisons with the Bonferroni adjustment for within-groups analyses; ${ }^{\mathrm{d}}$ Weight status categories were established according to Cole et al. (2000) by BMI, age and gender.

${ }^{*} p<.05, \dagger p<.001$ post-hoc pairwise comparisons with the Bonferroni adjustment for the between-groups analyses.

However, for the average percentage of total time the post-hoc within-group pairwise comparisons with the Bonferroni adjustment showed statistically significant higher MVPA values in PE than in SR and $\operatorname{AS}(p<.001)$, whereas no significant differences between SR and AS were found $(p=1.000)$.

\section{Gender}

The two-way ANCOVA results indicated statistically significant interaction effects on MVPA levels $(\mathrm{p}<.05)$. Subsequently, the post-hoc betweengroup pairwise comparisons with the Bonferroni adjustment showed statistically significant higher MVPA levels for boys in PE, SR and AS ( $p<.05)$ (except for AS on the average total time and average percentage of achieving the daily recommended MVPA that tended to be significant; $p=.072$ and .074 , respectively). Regarding the within-group pairwise comparisons, both boys and girls showed statistically significant greater values of average total time and average percentage of achieving the daily recommended MVPA in AS than in PE and SR, and higher MVPA levels in PE than in $\mathrm{SR}(\mathrm{p}<.001)$. However, for the average percentage of total time the within-group pairwise comparisons showed that boys had statistically significant higher MVPA values in PE than in SR and AS ( $<<.001)$, whereas no statistically significant differences between SR and AS were found ( $p>05)$. On the other hand, for the average percentage of total time the within-group pairwise comparisons showed that girls had statistically significant higher MVPA values in PE than in SR and AS $(\mathrm{p}<.001)$ and higher MVPA values in AS than in SR $(\mathrm{p}<.05)$.

\section{Weight status}

The two-way ANCOVA results did not find statistically significant interaction effects on MVPA levels ( $p>05$ ). Additionally, the post-hoc betweengroup pairwise comparisons with the Bonferroni adjustment did not show statistically significant differences between not-overweight and overweight students in PE, SR or AS ( $>$ >05). Regarding the within-group pairwise comparisons, both not-over- 
weight and overweight participants showed statistically significant greater values of average total time and average percentage of achieving the daily recommended MVPA in AS than in PE and SR, and greater MVPA levels in PE than in SR $(\mathrm{p}<.001)$. However, for the average percentage of total time the within-group pairwise comparisons showed that both not-overweight and overweight students had statistically significant higher MVPA values in PE than in SR and AS $(p<.05)$, meanwhile no statistically significant differences between SR and AS were found $(\mathrm{p}=1.000)$.

\section{Discussion and conclusions}

The first purpose of the present study was to compare the objectively-measured MVPA levels between PE, SR, and AS in the Chilean secondary school students. The results of this study revealed that, overall, students achieved higher values of average total time and average percentage of achieving the daily recommended MVPA in AS than in PE and SR, and greater MVPA values in PE than in SR. However, taking into account the total time monitored in each period, during PE sessions adolescents had a higher percentage of being involved in MVPA than during SR and AS time, whereas between SR and AS differences were not found. Finally, it must be mentioned that when summing up the three measured periods (i.e., PE, SR and AS), only $16 \%$ of the analyzed adolescents achieved the daily recommendation of $60 \mathrm{~min}$ of MVPA.

Viciana et al. (2016) compared the accelerometer-measured MVPA levels in PE, SR and AS in the Spanish adolescents. Similarly to the present study, these authors found out that, overall, the Spanish students achieved higher values of average total time and average percentage of achieving the daily recommended MVPA in AS than in PE and SR, and greater MVPA values in PE than in SR. Unfortunately, the authors did not compare the adolescents' MVPA levels taking into account the average percentage of total time monitored in each period. On the other hand, Mayorga-Vega and Viciana (2015) compared the average percentage of total time monitored of objectively-measured MVPA levels by a SenseWear $\mathrm{Pro}_{2}$ Armband in PE, SR and extra-curricular organized sports in Spanish adolescents. In contrast with the results of the present study, these authors found out that there were no statistically significant differences in adolescents' MVPA levels between PE and SR. It must be highlighted that, as the authors acknowledged, due to the purposes of their study the inclusion criterion was that students participated in extra-curricular organized sports and, therefore, only the participants with a higher motivation level could be selected. For that reason, contrary to the present study, the results of their study should only be generalized to active adolescents. Mayorga-Vega and Viciana (2015) also found that adolescents' MVPA levels were higher in extra-curricular organized sports than in PE and SR. In addition to the above mentioned differences in the sample, it also should be noticed that MVPA levels were analyzed during extra-curricular organized sports (i.e., sports sessions) instead of AS or leisure-time as in the present study, which clearly could explain those differences.

Previous authors have highlighted the importance of structured periods of PA, such as PE sessions, for contributing to students' daily PA levels (Brusseau, Kulinna, Tudor-Locke, van der Mars, \& Darst, 2011; Kretschmann, 2014; WHO, 2008), especially among less active students (Raustorp, Boldemann, Johansson, \& Mårtensson, 2010). Unfortunately, in the present study no student achieved the recommendation of being involved in MVPA at least $50 \%$ of the PE lesson time. Mixed evidence has been found because in some previous studies students achieved the recommended time (Dudley, Okely, Cotton, Pearson, \& Caputi, 2012; Kretschmann, 2014) and in others they did not (Marmeleira, Aldeias, \& Graca, 2012; Raustorp, et al., 2010). Specific intervention programs during PE classes have been effective, compared with usual practice, in increasing on average $24 \%$ of the time students have been involved in MVPA (Lonsdale, et al., 2013). Consequently, this kind of interventions would contribute significantly to the overall students' MVPA levels, increasing the percentage of students that meet the daily recommendations of MVPA. In this line, policy-makers of WHO state members such as Chile are encouraged to ensure that PE classes contribute to the overall students' daily MVPA (WHO, 2008). For this purpose, policies and actions of those countries should give priority to frequency and intensity of PE classes (WHO, 2008). Unfortunately, besides the limited PE time allocation in secondary school $(90 \mathrm{~min} /$ week) (Hardman, et al., 2014), the results of the present study reported that the Chilean secondary students had a low intensity PA during PE classes. Therefore, policy-makers are encouraged to provide high-quality daily PE classes in order to effectively contribute to the students' daily recommended MVPA.

Since in PE classes adolescents do not meet the recommended MVPA levels (WHO, 2006), extracurricular activities may help to supplement MVPA levels achieved in the PE classes (WHO, 2008). For instance, the effectiveness of the SR environment to promote PA has been considered as a key complementary setting (Ridgers et al., 2006). However, the results of the present study showed that, on average, the students accumulated only $7.4 \%$ of the daily recommended MVPA (i.e., $4.4 \mathrm{~min}$ ). Meanwhile Viciana et al. (2016) found that the Spanish adolescents accumulated just $4.4 \%$ of the daily MVPA 
recommendations (i.e., $2.6 \mathrm{~min}$ ). Although Viciana et al. (2016) found a lower achievement of the daily recommended MVPA, when the percentage of MVPA regarding the total time was taken into account, the values were approximately equal ( $7 \%$ in the present study and 9\% in the Viciana's et al. 2016, study). Regarding the studies with elementary schoolchildren, the contributions of SR are very heterogeneous ranging from 5 to $40 \%$ of the daily recommended MVPA (Ridgers, et al., 2006). Although specific intervention programs, such as markings and/or games equipment, could be effective in increasing students' MPVA levels during SR time, currently there is a need for more evidence of SR-based interventions, especially among adolescents since there is a lack of related intervention research (Parrish, Okely, Stanley, \& Ridgers, 2013).

Afterschool activities have also been highlighted as key measures to supplement MVPA levels achieved in PE classes (WHO, 2008). The results of the present study showed that AS was the period that contributed to the daily recommended MVPA more than PE and SR, achieving 36\% of the recommended 60 min (i.e., $22 \mathrm{~min}$ ). Recently Brooke, Corder, Atkin, and van Sluijs (2014) found, in a meta-analysis, that children and adolescents achieve on average $55 \%$ of the daily recommended MVPA levels during AS, but the findings of the analyzed studies were very heterogeneous ranging from $17 \%$ to $115 \%$. Additionally, it must be highlighted that Brooke et al. (2014) pooled both children and adolescents in their analyses and previous studies have confirmed a drop in the MVPA time throughout the years during the AS period (Arundell, et al., 2013), which could explain a lower achievement compared with the average obtained in Brooke's et al. (2014) meta-analysis.

The second purpose of the present study was to examine the influence of gender and weight status on the students' objectively-measured MVPA levels during PE lessons, SR and AS in the Chilean secondary school students. The results of the current study showed a gender-related influence on MVPA, finding higher values during PE, SR and AS for boys than for girls (for AS the average total time and average percentage of the daily recommended MVPA tended to be significant). Regarding the within-group pairwise comparisons, both boys and girls showed the same tendency as in the whole sample results, except for the girls who achieved greater relative MVPA values during AS than SR. In this line, previous findings found that in the majority of studies with secondary school students boys were involved in MVPA for more time than girls in each of these contexts (Fairclough \& Stratton, 2005; Slingerland, et al., 2012; Viciana, et al., 2016). Whilst the reasons behind these gender differences are not widely established, it has been suggested that boys may view these contexts as opportunities to compete, while girls might view them as opportunities to socialize with friends, especially in the unstructured contexts such as SR (Blatchford, Baines, \& Pellegrini, 2003). A lower motivation toward PA in girls than in boys (Martínez-Baena \& Mayorga-Vega, 2014) or gender-sport stereotypes (Boiche, Plaza, Chalabaev, Guillet-Descas, \& Sarrazin, 2014) could also explain these differences.

As regards the influence of the students' weight status, the results of the present study did not find differences in MVPA levels between the not-overweight and overweight adolescents. Although weight status-related influence on MVPA has had contrasting results, finding positive, negative and even no relationship (Fairclough \& Stratton, 2005; Gao, Oh, \& Sheng, 2011; Kremer, Reichert, \& Hallal, 2012; Mayorga-Vega \& Viciana, 2015; Ridgers, et al., 2012; Viciana, et al., 2016), as in the present study, most previous studies did not find differences between students with different weight status during PE classes (Fairclough \& Stratton, 2005; Kremer, et al., 2012; Viciana, et al., 2016), SR (Mayorga-Vega \& Viciana, 2015; Ridgers, et al., 2012; Viciana, et al., 2016) or extra-curricular sport (Mayorga-Vega \& Viciana, 2015). Further studies regarding this variable are necessary in order to clarify the relationship between adolescents' weight status and their MVPA levels in different environments.

The main strength of the present study is objectively-estimated MVPA levels. Unlike the self-report PA instruments (Sternfeld \& GoldmanRosas, 2012), ActiGraph accelerometers have shown to be highly reliable and valid monitors for assessing MVPA among adolescents (SantosLozano, et al., 2013; Trost, et al., 2011). However, the present study has some limitations that should be also acknowledged. The first limitation was related to the design used, because a cross-sectional design does not allow causal inferences about the relationships between the studied variables. Other limitations were related to a relatively small sample. Examining the adolescents' MVPA levels with small samples provides a lower generalization power than large-sized studies. A relatively low number of participants did not allow to examine the influence of individual factors through a fully hierarchical analysis approach where it would have analyzed the overall interactions (e.g., MVPA of the overweight girls). However, in the current study the not-analyzed individual factor was statistically controlled (i.e., ANCOVA instead ANOVA) and, therefore, it could reasonably be considered not to be a potential confounder.

Finally, it should be highlighted that the comparison of time that students spend in MVPA during these three contexts is complex due to the differences in particular durations. Since in the present 
study AS was defined as "out-of-school" or extracurricular time (i.e., from the end of the school schedule until the end of the day), it is not surprising that this period had a greater contribution to the daily recommended MVPA than PE and SR. However, when the percentage relative to the total time was taken into account, $\mathrm{PE}$ lessons had the greatest relative contribution, whereas no significant differences between SR and AS were found. This preliminary evidence could inform and guide future policy considering the promotion of PA among adolescents. Policymakers are encouraged to increase the number of curricular PE classes and teachers to ensure that a greater portion of PE class time is actually spent on MVPA, especially among adolescent girls. Additionally, since the contribution of PE lessons is clearly insufficient to achieve the recommended 60 min of daily MVPA, parents, teachers and institutions should promote the increase in students' MVPA levels during SR and AS.

\section{References}

Arundell, L., Ridgers, N.D., Veitch, J., Salmon, J., Hinkley, T., \& Timperio, A. (2013). 5-year changes in afterschool physical activity and sedentary behavior. American Journal of Preventive Medicine, 44(6), 605-611.

Bauman, A.E., Sallis, J.F., Dzewaltowski, D.A., \& Owen, N. (2002). Toward a better understanding of the influences on physical activity: The role of determinants, correlates, causal variables, mediators, moderators, and confounders. American Journal of Preventive Medicine, 23(2 Suppl), 5-14.

Bland, J.M., \& Altman, D.G. (1996). Transforming data. British Medical Journal, 312(7033), 770.

Blatchford, P., Baines, E., \& Pellegrini, A. (2003). The social context of school playground games: Sex and ethnic differences, and changes over time after entry to junior school. British Journal of Developmental Psychology, 21(4), 481-505.

Boiche, J., Plaza, M., Chalabaev, A., Guillet-Descas, E., \& Sarrazin, P. (2014). Social antecedents and consequences of gender-sport stereotypes during adolescence. Psychology of Women Quarterly, 38(2), 259-274.

Brooke, H., Corder, K., Atkin, A., \& van Sluijs, E. (2014). A systematic literature review with meta-analyses of withinand between-day differences in objectively measured physical activity in school-aged children. Sports Medicine, 44(10), 1427-1438.

Brusseau, T.A., Kulinna, P.H., Tudor-Locke, C., van der Mars, H., \& Darst, P.W. (2011). Children's step counts on weekend, physical education, and non-physical education days. Journal of Human Kinetics, 27, 123-134.

Burrows, R., Díaz, E., Sciaraffia, V., Gattas, V., Montoya, A., \& Lera, L. (2008). Hábitos de ingesta y actividad física en escolares, según tipo de establecimiento al que asisten . [Dietary intake and physical activity in school age children. In Spanish]. Revista Médica de Chile, 136(1), 53-63.

Cole, T.J., Bellizzi, M.C., Flegal, K.M., \& Dietz, W.H. (2000). Establishing a standard definition for child overweight and obesity worldwide: International survey. BMJ, 320(7244), 1240-1243.

Cortinez-O’Ryan, A., \& Aguilar-Farias, N. (2017). ¿Chile está comprometido con la actividad física de sus niños? Reporte de Notas chileno sobre la actividad física en niños y adolescentes 2016 [Is Chile committed to its children's physical activity? Chilean Report on physical activity in children and adolescents 2016. In Spanish]. Temuco, Chile.

Dudley, D.A., Okely, A.D., Cotton, W.G., Pearson, P., \& Caputi, P. (2012). Physical activity levels and movement skill instruction in secondary school physical education. Journal of Science and Medicine in Sport, 15(3), 231-237.

Fairclough, S., \& Stratton, G. (2005). Physical activity levels in middle and high school physical education: A review. Pediatric Exercise Science, 17(3), 217-236.

Gao, Z., Oh, H., \& Sheng, H. (2011). Middle school students' body mass index and physical activity levels in physical education. Research Quarterly for Exercise and Sport, 82(1), 145-150.

Hardman, K., Murphy, C., Routen, A., \& Tones, S. (2014). UNESCO-NWCPEA: World-wide survey of school physical education. Paris: UNESCO.

International Society for the Advancement of Kinanthropometry. (2001). International standards for anthropometric assessment. Underdale: International Society for the Advancement of Kinanthropometry.

Kremer, M.M., Reichert, F.F., \& Hallal, P.C. (2012). Intensity and duration of physical efforts in physical education classes. Revista de Saude Publica, 46(2), 320-326.

Kretschmann, R. (2014). Objective measurement of physical activity levels in everyday physical education. Research Quarterly for Exercise and Sport, 85(S1), S143.

Lee, H., Tamminen, K., Clark, A., Slater, L., Spence, J., \& Holt, N. (2015). A meta-study of qualitative research examining determinants of children's independent active free play. International Journal of Behavioral Nutrition and Physical Activity, 12, 5. 
Longmuir, P., Colley, R., Wherley, V., \& Tremblay, M. (2014). Risks and benefits of childhood physical activity. Lancet. Diabetes and Endocrinology, 2(11), 861-862.

Lonsdale, C., Rosenkranz, R.R., Peralta, L.R., Bennie, A., Fahey, P., \& Lubans, D.R. (2013). A systematic review and meta-analysis of interventions designed to increase moderate-to-vigorous physical activity in school physical education lessons. Preventive Medicine, 56(2), 152-161.

Marmeleira, J.F.F., Aldeias, N.M.C., \& da Graca, P.M.D.S.M. (2012). Physical activity levels in Portuguese high school physical education. European Physical Education Review, 18(2), 191-204.

Martínez-Baena, A.C., \& Mayorga-Vega, D. (2014). Gender differences in motivation towards physical activity in adolescents in Granada. Revista Internacional de Deportes Colectivos, 19, 89-90.

Mayorga-Vega, D., \& Viciana, J. (2014). Adolescents' physical activity in physical education, school recess, and extracurricular sport by motivational profiles. Perceptual and Motor Skills, 118(3), 663-679.

Mayorga-Vega, D., \& Viciana, J. (2015). Differences in physical activity levels in school-based contexts: Influence of gender, age, and body weight status. Kinesiology, 47(2), 151-158.

Moreno, L., Concha, F., \& Kain, J. (2012). Movement intensity of children during physical education classes in public schools: Results according to the type of professional that teaches the class. Revista Chilena de Nutrición, 39(4), 123-128.

Muros, J.J., Cofre-Bolados, C., Zurita-Ortega, F., Castro-Sanchez, M., Linares-Manrique, M., \& Chacon-Cuberos, R. (2016). Relación entre condición física, actividad física y diferentes parámetros antropométricos en escolares de Santiago (Chile) [Relationship between physical fitness, physical activity, and different anthropometric parameters in school children in Santiago (Chile). In Spanish.] Nutrición Hospitalaria, 33(2), 314-318.

Parrish, A.M., Okely, A.D., Stanley, R.M., \& Ridgers, N.D. (2013). The effect of school recess interventions on physical activity: A systematic review. Sports Medicine, 43(4), 287-299.

Poitras, V., Gray, C., Borghese, M., Carson, V., Chaput, J., Janssen, I., Katzmarzyk, P., et al. (2016). Systematic review of the relationships between objectively measured physical activity and health indicators in school-aged children and youth. Applied Physiology, Nutrition, and Metabolism, 41(6), S197-S239.

Raustorp, A., Boldemann, C., Johansson, M., \& Mårtensson, F. (2010). Objectively measured physical activity level during a physical education class: A pilot study with Swedish youth. International Journal of Adolescent Medicine and Health, 22(4), 469-76.

Ridgers, N.D., Salmon, J., Parrish, A.M., Stanley, R.M., \& Okely, A.D. (2012). Physical activity during school recess: A systematic review. American Journal of Preventive Medicine, 43(3), 320-328.

Ridgers, N.D., Stratton, G., \& Fairclough, S.J. (2006). Physical activity levels of children during school playtime. Sports Medicine, 36(4), 359-371.

Santos-Lozano, A., Santin-Medeiros, F., Cardon, G., Torres-Luque, G., Bailon, R., Bergmeir, C., Ruiz, J.R., et al. (2013). Actigraph GT3X: Validation and determination of physical activity intensity cut points. International Journal of Sports Medicine, 34(11), 975-982.

Silva, P., Aires, L., Santos, R.M., Vale, S., Welk, G., \& Mota, J. (2011). Lifespan snapshot of physical activity assessed by accelerometry in Porto. Journal of Physical Activity and Health, 8(3), 352-360.

Silva, P., Sousa, M., Sá, C., Ribeiro, J., \& Mota, J. (2015). Physical activity in high school during "free-time” periods. European Physical Education Review, 21(2), 135-148.

Slingerland, M., Borghouts, L.B., \& Hesselink, M.K.C. (2012). Physical activity energy expenditure in Dutch adolescents: Contribution of active transport to school, physical education, and leisure time activities. Journal of School Health, 82(5), 225-232.

Sternfeld, B., \& Goldman-Rosas, L. (2012). A systematic approach to selecting an appropriate measure of self-reported physical activity or sedentary behavior. Journal of Physical Activity and Health, 9(S1), S19-S28.

Thomas, J.R., Nelson, J.K., \& Silverman, S.J. (2011). Research methods in physical activity (6 ${ }^{\text {th }}$ ed.). Champaign, IL: Human Kinetics.

Trost, S.G., Loprinzi, P.D., Moore, R., \& Pfeiffer, K.A. (2011). Comparison of accelerometer cut points for predicting activity intensity in youth. Medicine and Science in Sports and Exercise, 43(7), 1360-1368.

Viciana, J., Martínez-Baena, A., \& Mayorga-Vega, D. (2015). Contribución de la educación física a las recomendaciones diarias de actividad física en adolescentes según el género; Un estudio con acelerometría. [Contribution of physical education to daily recommendations of physical activity in adolescents according to gender: A study with accelerometry. In Spanish]. Nutrición Hospitalaria, 32(3), 1246-1251.

Viciana, J., Mayorga-Vega, D., \& Martinez-Baena, A. (2016). Moderate-to-vigorous physical activity levels in physical education, school recess and after-school time. Influence of gender, age, and weight status. Journal of Physical Activity and Health, 13(10), 1117-1123.

Viciana, J., Mayorga-Vega, D., \& Parra Saldías, M. (2017). Adolescents' physical activity levels on physical education and non-physical education days according to gender, age, and weight status. European Physical Education Review. In press.

World Health Organization. (2006). Promoting physical activity in schools: An important element of a health-promoting school. Geneva: WHO. 
World Health Organization. (2008). School policy framework: Implementation of the WHO global strategy on diet, physical activity and health. Geneva: WHO.

World Health Organization. (2014). Global status report on noncommunicable diseases 2014. Geneva: WHO.

Zimmermann-Sloutskis, D., Wanner, M., Zimmermann, E., \& Martin, B.W. (2010). Physical activity levels and determinants of change in young adults: A longitudinal panel study. International Journal of Behavioral Nutrition and Physical Activity, 7, 2.

Submitted: September 8, 2016

Accepted: October 2, 2017

Published Online First: October 17, 2017

Correspondence to:

Daniel Mayorga-Vega, Ph.D.

Department of Physical Education and Sport

University of Granada

Alfacar Street, 18011, Granada, Spain

Phone number: (0034) 958246641

Fax number: (0034) 958244369

E-mail: dmayorgavega@gmail.com

\section{Acknowledgments}

The authors gratefully acknowledge all the participating students and their parents, without whom the present study could not have been carried out. Authors also acknowledge all the members of the school for their enthusiasm and collaboration, especially the school principal and the physical education teachers. We thank Anna Szczesniak for the English revision. Daniel Mayorga-Vega was supported by a research grant of the Research Own Plan of the Vice President of Research and Transfer of the University of Granada. 